\section{Profit or perish even worse than publish or perish}

\section{SIR - Michael Alvarez, in his Recruiters} article 'System-ready scientists' (Nature 447, 612 ; 2007) advises young scientists to consider how they can fit into and enhance the labour force, even though this course might seem dehumanizing to them. He advises universities to gather information from government and industry about their 'design specifications' for incoming talent, to help them develop graduate training programmes that produce suitably qualified trainees.

I believe such an approach is a backwards step. Many scientists study and do research out of irrepressible curiosity and sheer love for the subject. It is true that the US academic funding system created a glut of postdoctoral researchers who have had to find alternatives to conventional career paths, but 'publish or perish' is a relatively harmless dictum compared with 'profit or perish'.

Rather than helping universities strip the creativity, intuition and joy of discovery from scientists while they train, government and industry should be willing to spend money, within their pragmatic frameworks, to acknowledge that scientific research is a fundamentally creative pursuit.

Edward Kiegle

Moonshine Mushrooms, PO Box 927, 251 Putnam Hill Road, Chester, Vermont 05143, USA

\section{Interdisciplinary research could pull cash into science}

SIR - James A. Smith and Gemma E. Carey, in Correspondence (Nature 447, 638-639), address the need for supportive environments if interdisciplinary research goals are to be achieved. Among other points, they mention that assessments of such research quality are made in single-subject committees in New Zealand, Australia and the United Kingdom.

I, and I am sure others, made similar points to a UK Parliamentary Science and Technology Committee general research review in 1999 (see www.parliament.thestationery-office.co.uk/pa/cm199900/ cmselect/cmsctech/196/196ap02.htm).

Several useful developments occurred as a result. Generic funding initiatives were set up in genomics, e-science and information technology, where interdisciplinary investigators and teams could apply to tackle broad research objectives. Discipline-hopping awards were established to encourage researchers to be mobile in their research interests. The UK Research Councils took a unified 'road show' around universities and institutes to take input from the research community. Articles were published in UK Research Councils newsletters, describing research-interface developments. Input was added to research assessments, to flag acrossthe-disciplines relevance.

These efforts did not succeed in achieving a unified science and engineering research council, with a single charter and unified management structure. However, I believe that the government made efforts to respond to criticisms and, as a result, put the United Kingdom in a more flexible position.

There remains another big issue on the block, as Philip Strange pointed out in Correspondence (Nature 448, 22; 2007): the ratio of grant proposals made to those funded can be between three and five to one. This is a very arbitrary measure of research quality. Seeing excellent proposals, agreed by referees and my own experience, finally get rejected, shows all too clearly that the 'unfunded ratio' is deeply flawed as a metric, at least at this level of underfunding. Perhaps interdisciplinary research could be the latest big idea for bringing new money into the United Kingdom's national research enterprise? John R. Helliwell

School of Chemistry, University of Manchester, Manchester M13 9PL, UK

\section{The 'hundred surnames' of China run into thousands}

SIR - I am writing to point out one misconception that may arise from your Editorial 'Asia on the rise' (Nature 447, 885; 2007). Although the most common names in China are known as 'the hundred surnames', there are many others in widespread use.

A recent survey by the Chinese Academy of Sciences found 4,100 surnames, of which 129 covered $87 \%$ of the population (Y. Yuan Chinese Nat. Geog. 2, 38-39; 2007, or see http://english.people.com.cn/ 200601/11/eng20060111_234647.html). This leaves nearly 200 million people using the other surnames.

The mistaken idea that only 100 surnames are used probably comes from a famous tenth-century booklet that is literally translated as A Hundred Family Names. However, in Chinese, 'a hundred' often just means a large number - in fact, the booklet itself included 504 surnames. The Grand Dictionary of Chinese Surnames (Y. Yuan and R. Du, Education and Science Press, Beijing, 1996 ) included 11,969 surnames, and 24,000 have been recorded in the past.

The practice of taking the mother's surname as well as the father's has often been proposed, but I doubt whether the Chinese government will take any measures to enforce it in the near future.

Dafeng Hui

Auburn University School of Forestry and Wildlife Sciences, 602 Duncan Drive,

Auburn, Alabama 36849, USA

\section{University speaks up in dispute over cancer centre}

SIR - As vice-president of public affairs at Arizona State University (ASU), I would like to give a different account of recent events from that put forward in Correspondence by Carl Djerassi ('Not so sunny view of the events in Arizona' Nature 447, 1052; 2007).

At ASU, as at most American research universities, positions funded by external grants are completely dependent on that funding. Robert Pettit, former director of the university's Cancer Research Institute (CRI), attempted to secure funding to continue his research, submitting proposals to both the National Cancer Institute and the National Oceanic and Atmospheric Association, but these were not selected by those agencies from among the many competing proposals. That is the sole reason why 22 staff and seven students working on Pettit's research team (not 60 individuals as Djerassi indicates) had to be reassigned or released.

The affected individuals were given a 30 -day notice of termination and offered outplacement support. Of the 22 permanent staff, seven were placed in comparable positions at ASU and two chose to retire.

Pettit remains a Regents professor in the department of chemistry and biochemistry with tenure at ASU. The non-renewal of his year-to-year administrative appointment as director of CRI was based on findings by the university provost, among other things, that Pettit had contravened policies of the Arizona Board of Regents and ASU.

Virgil Renzulli

Arizona State University, PO Box 872503,

Tempe, Arizona 85287-2503, USA

\section{Climate information helps homeowners make choices}

SIR - You raise the question in your News story 'Website homes in on climate hazards' (Nature 447, 360-361; 2007) of whether homeowners can make good use of the climate risk information provided by our company. We have had tens of thousands of visitors to our site, and thousands of requests for reports, indicating that homeowners want this information to make their own property risk assessment, given the potential risks to their safety, retirement equity and quality of life. We have heard clearly that people feel empowered by having this information to assess their risk for themselves, rather than waiting for the possibility that an insurance company's underwriting changes will affect their options and their property value.

David Purcell

Climate Appraisal Services LLC, 25 Abbey Road, Easton, Connecticut 06612, USA 